\title{
AC 2012-4991: PREREQUISITE COURSES AND RETENTIVITY AS A CHALLENGE
}

\section{Dr. Robert E. Efimba P.E., Howard University}

Robert E. Efimba, Sc.D., P.E., Associate Professor in the Department of Civil and Environmental Engineering at Howard University in Washington, D.C., received his four degrees in civil engineering and structural mechanics from MIT, and is a registered Professional Engineer in Virginia, Maryland, and D.C. He is listed in Who's Who in Engineering, was named the 2010 Outstanding Advisor of Tau Beta Pi, was installed as a 2011-2014 Governor of ASCE's Region 2, and is a past recipient of the ASCE Moisseiff Award for best paper in the field of structural design. His research is on finite elements in design applications and engineering mechanics education.

\section{Dr. Tori Rhoulac Smith, Howard University}

Tori Rhoulac Smith began as an Assistant Professor in the Department of Civil Engineering at Howard University in 2003. In this position, she served as an academic and research Advisor, instructor for a variety of undergraduate and graduate engineering courses, and researcher on traffic engineering and engineering education projects. Feeling an overwhelming desire to work more directly on identifying and meeting the needs of increased recruitment, retention, and achievement of traditionally-underrepresented minority students in engineering disciplines, she shifted her career focus and now serves as an instructor and undergraduate education coordinator for the Department. Her primary focus is now undergraduate teaching, advising, curriculum, and evaluation. Rhoulac Smith earned master's of science and doctorate of philosophy degrees in civil engineering from North Carolina State University in Raleigh, N.C., in 2000 and 2003 respectively. She also earned a bachelor's of science degree in civil engineering from Howard University in 1998. 


\title{
Prerequisite Courses and Retentivity as a Challenge for Students in Engineering Mechanics
}

\begin{abstract}
A recurring problem for teachers of engineering mechanics is that many students sign up to start their courses when they are not quite ready for them. This situation of unreadiness may be due to lack of adequate preparation. At first, it is easy to want to ascribe the problem to lack of coverage of pertinent material in the prerequisite course(s). However, the more likely cause is an amazing amnesia that leaves the students with very few of the important concepts learned in the prerequisite courses that are needed for the mechanics course that they are about to start. This phenomenon is observed even among some of the best students who get top grades in the prerequisite courses by demonstrating mastery of the material, but then "draw a blank" when it comes time to apply that material in a subsequent course. This paper explores the problem of unreadiness and the effectiveness of taking time to strengthen students' prerequisite knowledge in a course using sophomore and junior mechanics classes.
\end{abstract}

\section{Introduction}

Engineering curricula are usually structured in such a way as to include a careful sequence of courses that require satisfactory completion of prerequisite courses before progressing to the next course. The accreditation process promotes this connectedness and sequencing in engineering curricula so that all courses collectively contribute to accomplishing student learning outcomes and program educational objectives. The ASCE Body of Knowledge also promotes an integrated curriculum with a technical core that includes mechanics. ${ }^{1}$ Still, "disjointedness" between courses is often apparent when students are asked to recall content from prerequisite courses. ${ }^{2}$ This unreadiness can be especially harmful in the course sequences that directly involve engineering mechanics as a foundational core, but the problem of unreadiness is universal. Indeed, as one reviewer of the abstract for this paper put it, this is "a topic that every professor is dying to hear the answers to."

Student unreadiness, in this paper, is defined as lacking needed content knowledge from prior courses. It is the commonly-observed phenomenon in which students are not prepared for a course because they have not retained concepts from prerequisite courses. Anecdotal evidence suggests that students are not ready to start a course in mechanics for any one or more of the following reasons:

1. They are taking the course out of sequence and, therefore, do not have the prerequisites;

2. They performed poorly or just barely passed the prerequisite course(s);

3. They performed well but have forgotten most of what they learned in the prerequisite course(s).

The first proposed reason for unreadiness can be easily solved by an effective advising system. Students must be prevented from registering for courses for which they do not have the prerequisites. Instructors should verify that each student enrolled in a course has, in fact, completed prerequisite course(s) with a passing grade and must have the authority to cancel the 
enrollment of those who have not. The remaining reasons are more difficult to address. Some institutions have created courses to replace common prerequisite courses and present needed concepts within the context of the engineering discipline. ${ }^{3}$ Others have altered the sequencing of courses to enhance students' opportunities to be successful. ${ }^{4}$ In the engineering mechanics sequence at the authors' institution, students are given a prerequisite test in an attempt to address poor performance or retention in prerequisite courses. Despite the many interventions that have been implemented to decrease unreadiness and increase achievement, there still remains a question as to the effectiveness of a strategy with different student populations. Do underclassmen (freshmen and sophomores) respond in the same way upperclassmen (juniors and seniors) do? Is a certain strategy more effective with underclassmen than upperclassmen? This paper explores the problem of unreadiness and the effectiveness of taking time to strengthen students' prerequisite knowledge in a course using sophomore and junior mechanics classes.

\section{Prerequisite Knowledge}

Informing students of prerequisite knowledge requirements is a recommended procedure for success in teaching mechanics that one of the authors uses in all his undergraduate and graduate courses. $^{5-8}$ The first day of class is used to thoroughly discuss the course policy, syllabus, and a list of itemized topics from prerequisite courses that are needed for success in the course. Such a list is shown in the Appendix. Written and oral notice is also given that, perhaps as early as the second day of class, a non-binding, optional, but highly recommended impromptu, open book, open notes test on the prerequisite materials will be given. This allows students time to gather and review notes and other materials from prerequisite courses prior to the test. Full resources are devoted to grading the tests so that students can receive and discuss their test results in the first week of class. Though it requires a sacrifice (better yet, investment) of time, it is important that all of this activity takes place during the first week of classes to ensure that students are ready to start the course.

A prerequisite test can be assembled quickly from concept questions that are provided in textbooks, such as Bedford and Fowler $(2008)^{9}$, Beer and Johnston (2007) ${ }^{10}$, and Hibbeler $(2004)^{11}$, which devotes an entire appendix to review questions for the FE exam. Questions can also be gathered from the "Mechanics Readiness Test" or a similar exam. ${ }^{12}$ The prerequisite tests used to gather data for this paper were created by the instructor, such as the sample in the Appendix. Exam questions vary from class to class for variety and novelty, but are occasionally repeated to classes in different semesters for the purpose of comparing student readiness.

Some instructors approach prerequisite knowledge as an assumed asset of their students, only to find as they immediately delve into the concepts for their courses that prerequisite knowledge is more of a deficiency than an asset. The state of student retention of prerequisite materials, however, suggests that prerequisite knowledge should be addressed at the start of each course, especially in engineering mechanics. In addition to a thorough discussion of solutions to prerequisite test problems, students involved in the data collection for this paper were also given a written, itemized list of the most common errors that were made on the test. This list was intended to guide the students to seriously review pertinent prerequisites for the course and strengthen any conceptual weaknesses. 


\section{Results}

The trends in comparison of prerequisite test and average exam scores indicate the obvious fact that adequate preparation, as verified in a prerequisite test, gives a student a better chance to perform well in a given mechanics course. Even employing strategies such as giving students a prerequisite concept inventory, graded test, explanation of solutions, and common errors to avoid, cannot reverse the effects of poor performance and retention in prerequisite courses.

Figure 1 shows the relationship between individual students' prerequisite test and average exam scores in two Statics classes with a total of 26 students, all sophomores, with the exception of about five upperclassmen, from a variety of engineering departments. Student names and identification numbers are withheld for privacy reasons.

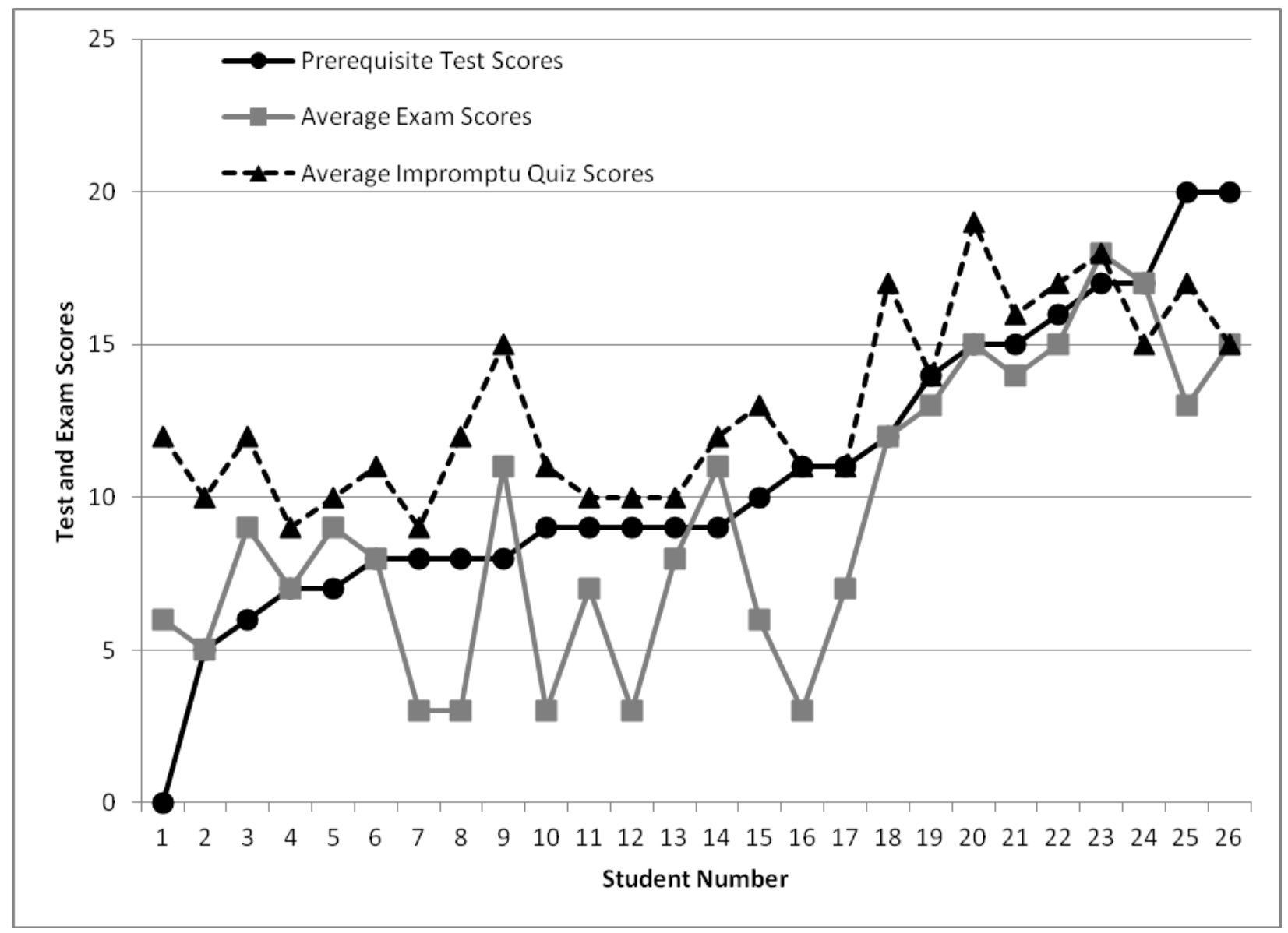

Figure 1. Prerequisite Test and Average Exam Scores in Statics

The fit of the trendlines $\left(\mathrm{R}^{2}\right)$ for prerequisite test scores to average exam scores and average impromptu quiz scores in Figure 2 are 0.53 and 0.52 , respectively. So, half of the variance in students' achievement in the class is explained by the prerequisite knowledge indicated by prerequisite test scores. This is a notable relationship that should encourage instructors to devote more time to strengthening prerequisite knowledge at the beginning of a course to enhance students' success. The goodness of fit decreases drastically when looking at this same relationship in the junior-level Mechanics of Materials course. Figure 3 presents the data based 
on 17 students in Mechanics of Materials. In this course, the $\mathrm{R}^{2}$ values for average exam scores and average impromptu quiz scores related to prerequisite test scores are 0.19 and 0.29 , respectively. This suggests that there are far more factors that affect students' success in more advanced mechanics courses than just prerequisite knowledge, though explaining $20 \%$ of the variance is not entirely inconsequential.

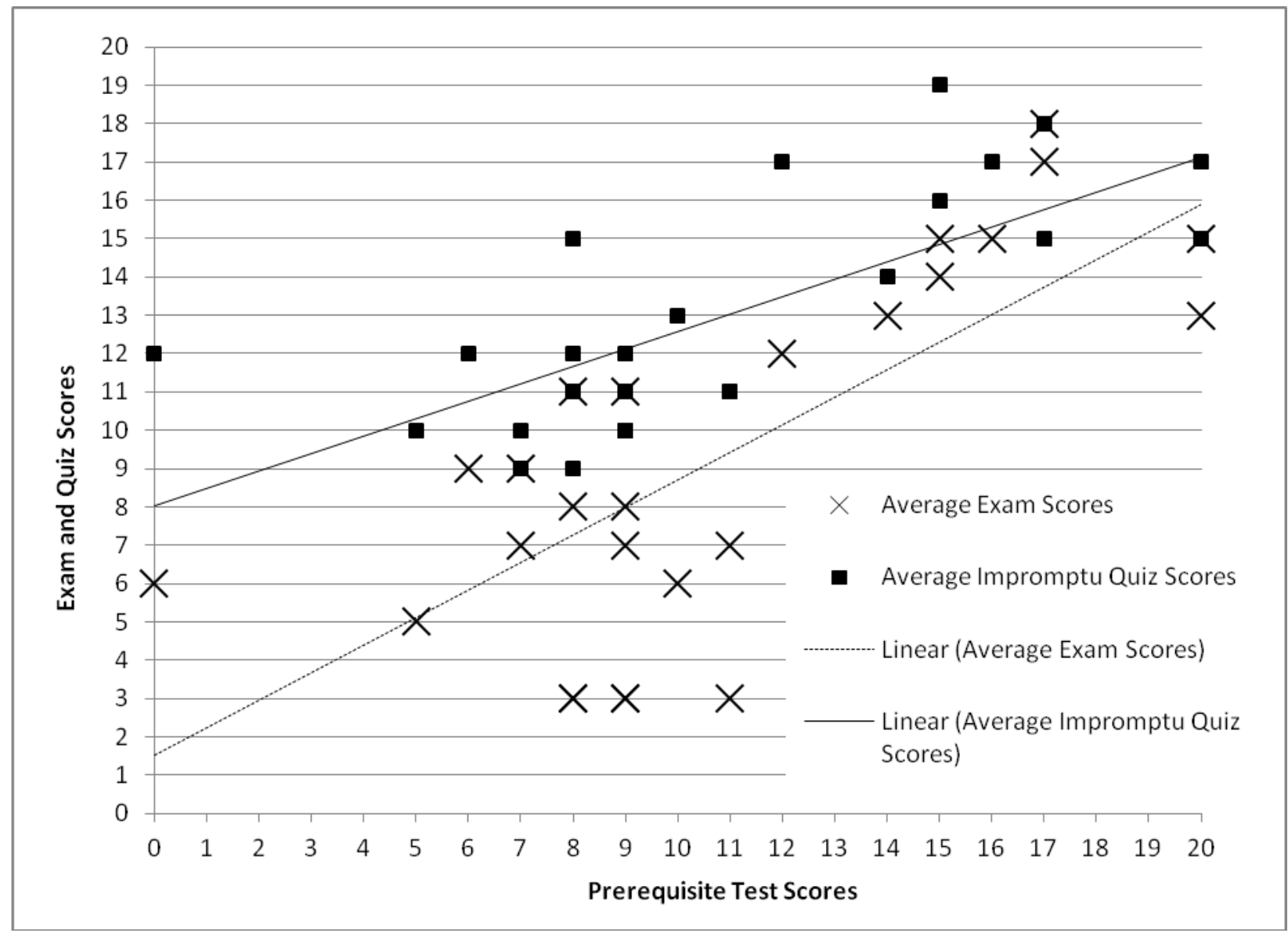

Figure 2. Scatter Plot of Prerequisite Test and Average Exam Scores in Statics

Interestingly, the relationship between prerequisite test scores and academic performance as indicated by quiz and exam scores in the junior-level Mechanics of Materials course varies from that of the sophomore Statics course. Students seemed to better utilize tools aimed at strengthening their prerequisite knowledge in this course, resulting in quiz and exam scores that are numerically higher, on average, than their prerequisite test scores. This is illustrated in Figure 4. Although the mean prerequisite test score and mean exam average are not statistically different in the underclassmen or upperclassmen data, this is likely due to the relatively small sample sizes and large variances. 


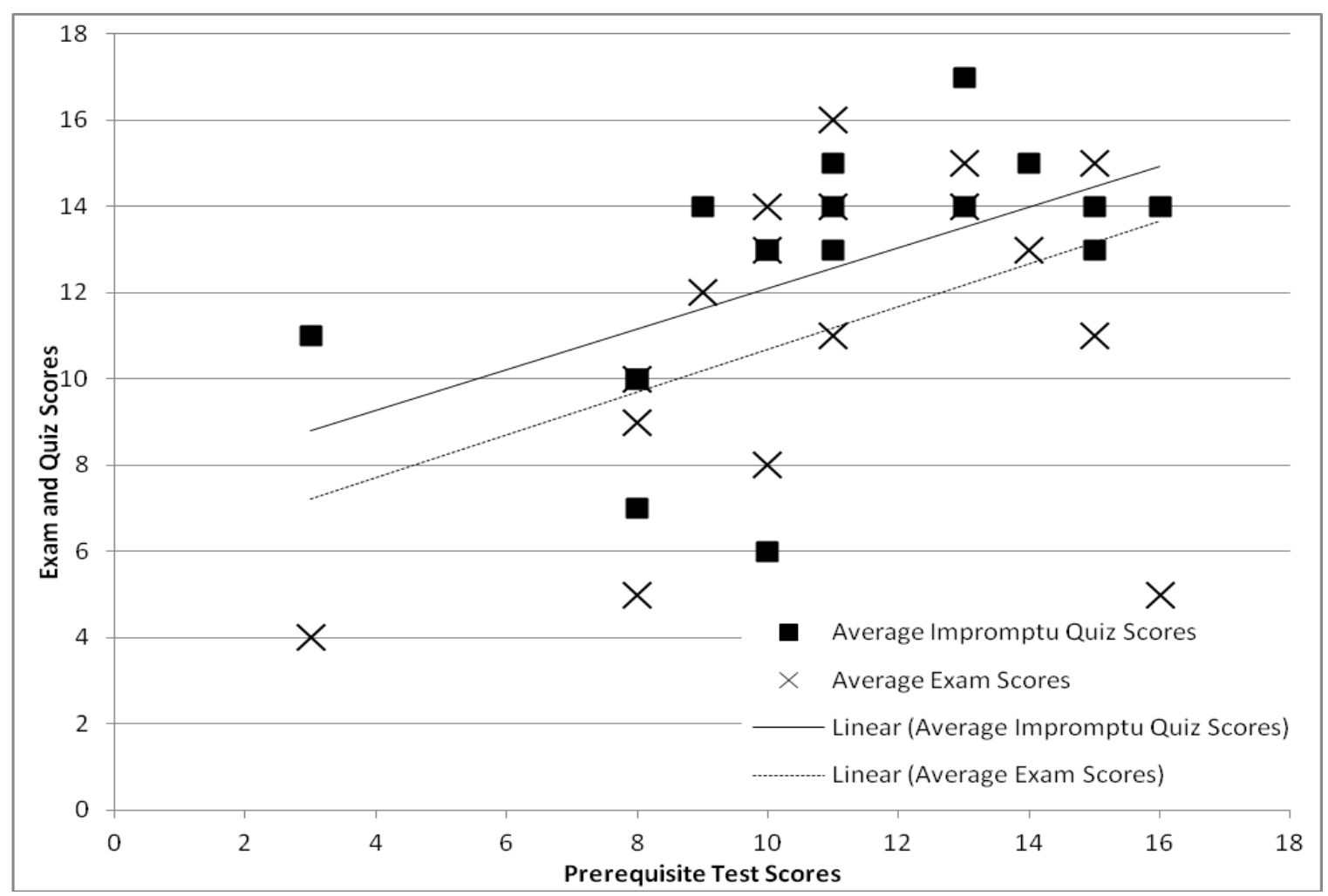

Figure 3. Scatter Plot of Prerequisite Test and Average Exam Scores in Mechanics of Materials

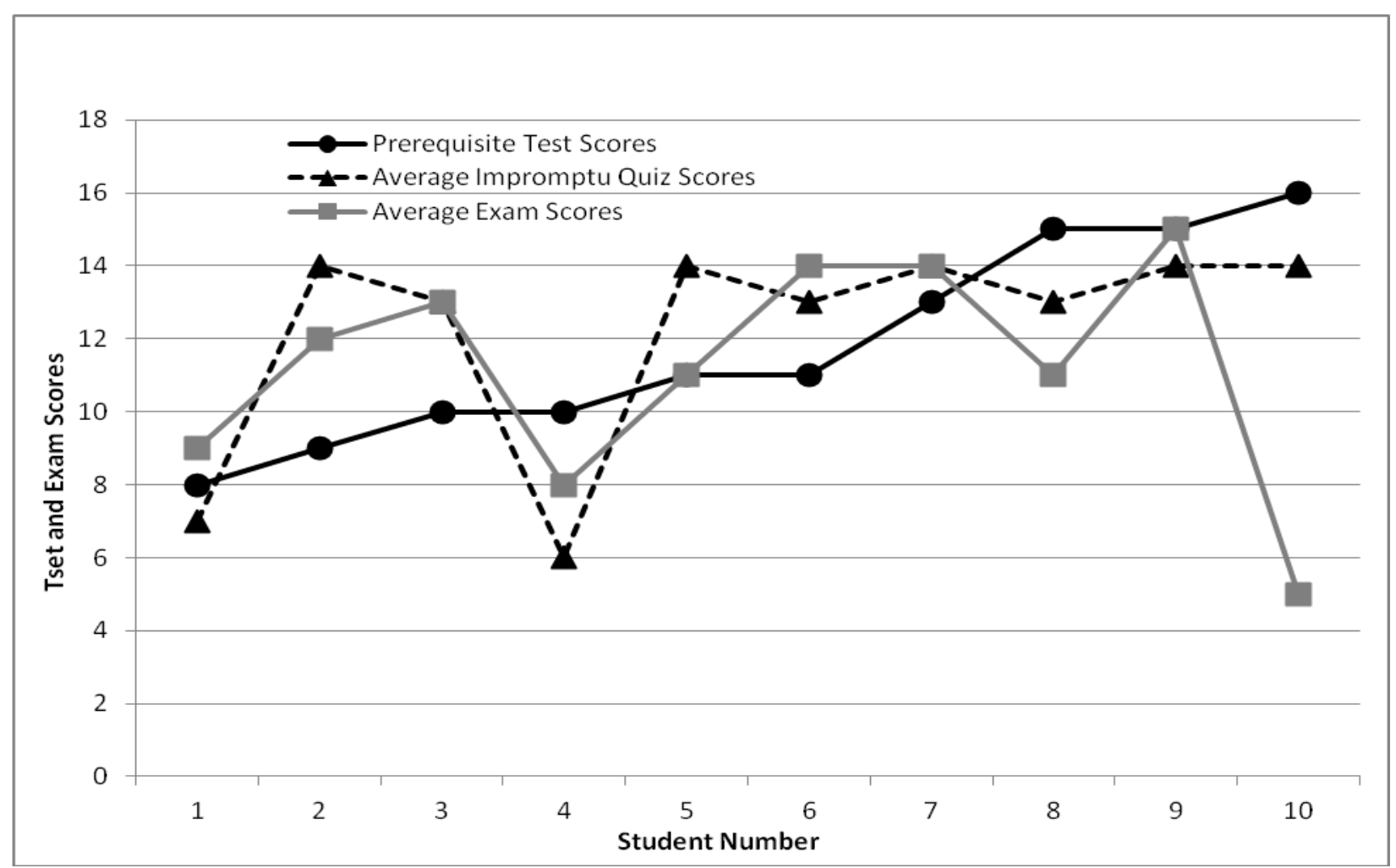

Figure 4. Prerequisite Test and Average Exam Scores in Mechanics of Materials 


\section{Conclusions}

Prerequisite knowledge is more of a vital factor in determining students' success in a mechanics course for underclassmen than for upperclassmen. Generally, a lower prerequisite test score resulted in higher exam and quiz scores for upperclassmen, while the achievement of underclassmen continued to be directly related to prerequisite knowledge throughout the course. This suggests that upperclassmen are more likely to regard warnings of unreadiness at the beginning of a course, as indicated by prerequisite test scores, and work to compensate for deficiencies in prerequisite knowledge. This also indicates that prerequisite testing, concept inventories and common error inventories are effective strategies for combating unreadiness in upperclassmen, more so than in underclassmen. This does not mean that attempts to combat unreadiness using prerequisite exams and similar strategies should be abandoned in mechanics classes for underclassmen. Even in a preliminary study such as this with relatively small sample sizes, the prerequisite testing still explained about $20 \%$ of the variance in average exam scores. Instructors should just be mindful that underclassmen are more likely to need additional measures to enhance their achievement in a mechanics course.

\section{Recommendations}

The prerequisite test should be seen as a diagnostic tool and used to help strengthen students' prerequisite knowledge for a course. Additional research is recommended to further study the effectiveness of the prerequisite exam to affect achievement in mechanics classes for all levels of students (underclassmen and upperclassmen). A coordinated, multi-university study would be especially meaningful to also study effects in different academic settings.

Also, in order to improve learning and teaching in mechanics, student preparation should begin long before a prerequisite test. Engineering faculty members should advance interest in and preparation for engineering fields and continue to encourage, promote and strengthen interest in pre-college initiatives such as the Mathcounts program of the National Society of Professional Engineers.

\section{Acknowledgements}

The authors thank their Chairperson in the Department of Civil and Environmental Engineering at Howard University, Dr. Kimberly Jones, and fellow colleagues for their advice and support. Most importantly, special thanks go to the students of the Department who also support and encourage the faculty, teaming with them to improve teaching and learning for all.

\section{References}

1. ASCE (2008), "Civil Engineering Body of Knowledge for the $21^{\text {st }}$ Century: Preparing the Civil Engineer for the Future," $2^{\text {nd }}$ ed., Prepared by the Body of Knowledge Committee of the Committee on Academic Prerequisites for Professional Practice, American Society of Civil Engineers. Reston, VA.

2. Felder, Richard M. and Rebecca Brent (2003), Designing and Teaching Courses to Satisfy the ABET Engineering Criteria, Journal of Engineering Education, 92 (1), pp.7-25 
3. Klingbeil, N.W., Mercer, R.E., Rattan, K.S., Raymer, M.L. and Reynolds, D.B. (2005) "The WSU Model for Engineering Mathematics Education" Proceedings of the 2005 American Society for Engineering Education Annual Conference \& Exposition, American Society for Engineering Education.

4. Ohland, Matthew W., Amy Yuhasz, and Benjamin Sill (2004), Identifying and Removing a Calculus Prerequisite as a Bottleneck in Clemson's General Engineering Curriculum, Journal of Engineering Education, pp. 253-257.

5. Efimba, R.E., and S.E. Zanganeh (1998), "Bridging Some Gaps in Engineering Education," Paper presented at the American Society for Engineering Education (ASEE) Middle Atlantic Regional Conference on "Engineering Education Without Boundaries," Washington, DC, November 6-7, A. Rubaai, ed., Proc. pp. 63 - 66.

6. Zanganeh, S.E., and R. E. Efimba (1995), "Making Statics Interesting," paper presented at a Chemical Engineering Session at the American Society for Engineering Education (ASEE) Annual Conference held in Anaheim, CA, June 25-28, Proc v.2, pp. 2199-2205

7. Zanganeh, S.E. and R.E. Efimba (1994). "A Computer-Integrated Approach to Teaching Engineering Mechanics," paper presented at the First ASCE Congress on Computing in Civil Engineering, Washington, DC, Proc. v.2, pp. 1265-1272.

8. Zanganeh, S.E, and R.E.Efimba (1997), "Integration of Design in Engineering Mechanics Courses: A Practical Approach," Paper presented at an ECSEL Coalition Workshop on "Learning by Design" held at Howard University, October 1997.

9. Bedford, A., and W. Fowler (2008, Engineering Mechanics: Statics, $5^{\text {th }}$ ed., Pearson/Prentice-Hall.

10. Beer, F.P., and E.R.Johnston (2007), Vector Mechanics for Engineers: Statics, $8^{\text {th }}$ ed., McGraw-Hill.

11. Hibbeler, R.C. (2004), Engineering Mechanics: Statics, $10^{\text {th }}$ ed., Pearson/Prentice-Hall.

12. Negahban, M (2000), "Results of Implementing a Computer-based Mechanics Readiness Program in Statics," Int. J. Engrg Educ, v. 16 n. 5, pp. 408-416. 


\section{Appendix}

\section{SAMPLE LIST OF PREREQUISITE CONCEPTS FOR STATICS}

\section{Arithmetic}

- Addition, subtraction, multiplication and division

- Order of operations through the rule of BEMDAS

- Highest common factor and lowest common multiple

- Bases, logarithms, and exponents

- Fractions, decimal notation and scientific notation

\section{Algebra}

- Expansion and factorization

- Formulation and solution of linear, quadratic and cubic equations in one variable

- Solution of simultaneous linear equations in 2 or 3 variables

- Ratios and the application of componendo and dividendo

\section{Geometry}

- Properties of a triangle (in general)

- Special properties of right-angle, isosceles, and equilateral triangles

- Properties of a parallelogram, rhombus, and regular polygons

- Properties of a circle, its segments, sectors, tangents and intersecting chords

- Properties of a cube, cuboid, prism, sphere, and hemisphere

- Notions of latitude and longitude

\section{Trigonometry}

- Basic functions (sine, cosine, and tangent) and the corresponding reciprocal functions (cosecant, secant, and cotangent, respectively) that relate the angles to the sides of a right triangle

- Sine and cosine rules for a general triangle

- Double-angle formulas and expressions for trigonometric functions of sums and differences of two angles

- Equations of a circle, ellipse, parabola, and hyperbola;

\section{Calculus}

- Differentiation and integration of polynomial, exponential, logarithmic, and trigonometric functions in one variable

- Determination of extreme values of such functions 


\section{$\underline{\text { SAMPLE PREREQUISITE TEST (STATICS) }}$}

Open Books and Notes. Calculators are allowed, but cell phones and all other electronic equipment must be shut off and put away. Credit will be given only for answers shown in the spaces provided on this sheet. The answer to each part of a question is worth one point. Any numerical answers should be given to no more than 3 significant digits, with units (if any).

1. A pound of sugar has a mass of slug $=$ $\mathrm{kg}$

and weighs $\mathrm{N}$

2. A meter stick has a length of $\mathrm{mm}=$ ins $=$ $\mathrm{ft}$

3. In scientific notation, $0.0004567=$ and $199.62=$

4. When $\mathrm{a}=2, \mathrm{~b}=5, \mathrm{c}=-8$, evaluate

$$
\begin{aligned}
& \mathrm{a}+\mathrm{b} \times \mathrm{c}-\mathrm{a}= \\
& \mathrm{b}-\mathrm{c}+\mathrm{a} /(\mathrm{b}-2 \mathrm{a})= \\
& 0.5 \sin (\mathrm{a}) \cos (\mathrm{a})= \\
& \sin (2 \mathrm{a})= \\
& \arcsin (\mathrm{a} / \mathrm{b})=
\end{aligned}
$$
(between 0 and 90) degrees $=$ $\mathrm{rad}$

5. Give all possible solutions for these equations

$$
\begin{aligned}
& 3 \mathrm{x}+7=-8, \quad \mathrm{x}= \\
& \mathrm{x}^{2}-7=9, \quad \mathrm{x}= \\
& \mathrm{x}^{2}+\mathrm{x}=3.75, \quad \mathrm{x}= \\
& 2 \mathrm{x}+3 \mathrm{y}=21 \text { and } 7 \mathrm{x}-2 \mathrm{y}=11, \mathrm{x}=
\end{aligned}
$$$$
\text { and } \mathrm{y}=
$$

6. For a pie with a 22 -inch circumference, the radius $=$

7. $15 \mathrm{mph}=$ $\mathrm{ft} / \mathrm{s}=$ $\mathrm{m} / \mathrm{s}=$ $\mathrm{km} / \mathrm{h}$

8. Approximately, the size of the class text is and the volume in both units systems is $\mathrm{x}$ $=$

9. One side of a triangle is of length $10 \mathrm{~mm}$, and makes angles of 45 and 75 degrees with the other two sides, whose lengths are and , and the area of the triangle $=$

10. For a rhombus of side $8 \mathrm{ft}$ and one interior 30 degree angle, area $=$

11. Identify by specific name each of the curves whose equations are given below and, where applicable, indicate a finite max and/or min value for $\mathrm{y}$ $\mathrm{x}+2 \mathrm{y}=6$

$\mathrm{x}^{2}+\mathrm{y}^{2}-25=0$

$\mathrm{y}=4 \mathrm{x}^{2}$ 
12. Evaluate the determinants of these matrices:
a) $2 \times 2$ matrix with rows: 21
c) $3 \times 3$ matrix with rows:

and $5 \quad 8$
b) 2 x 2 matrix with rows: 32
$\begin{array}{lll}2 & 0 & 7\end{array}$
$\begin{array}{lll}3 & 2 & 1\end{array}$
and $6 \quad 5$
$\begin{array}{lll}6 & 5 & 8\end{array}$

\section{ADDITIONAL PREREQUISITE TEST QUESTIONS}

13. Approximately, a US quarter (coin) has a
a) diameter $=$ in $=$ $\mathrm{mm}$
b) the perimeter $=$ in $=$ $\mathrm{mm}$
c) the area = in $^{2}=$ $\mathrm{mm}^{2}$

14. $5 / 8+2 / 3-30 \%$ of $\left.2^{-2} \times 3 / 5+(8-3) / 6=a\right)$ $($ decimal fraction $)=c$ ) $($ rational fraction $)=b)$ (percentage)

15. Name the curve $\&$ give all possible solutions for $\mathrm{x}$ in these equations:
i. $2 \mathrm{x}-8=2+\mathrm{x}$
ii. $\mathrm{y}-\mathrm{x}^{2}=0$
iii. $x^{2}-8 x=-15$
iv. $x^{3}-9 x^{2}+23 x-15=0$

16. Approximately, the instructor in this course has a
a. height $=$ in $=$
b. weight $=$ lbs $=$ $\mathrm{m}$
c. mass $=$ (give USCS units) $=$ (give SI units)

17. For this sheet of paper, approximately,

i. the perimeter $=$

ii. the area = in $=$ in $^{2}=$ $\mathrm{mm}$

$=\mathrm{in}^{2}=\longleftarrow \mathrm{mm}^{2}$

18. $2 / 3-40 \%$ of $1 / 2 \times 3 / 5+8 /(3+7)=a)$ decimal fraction) $=\mathrm{c}$ ) $($ rational fraction $)=b)$ (percentage)

19. Simplify these expressions:
a) $2-\sin ^{2} b-\cos ^{2} b=$
b) $1+\tan ^{2} b$
c) $(a-b) /\left(b^{2}-a^{2}\right)=$ 